\title{
Miller-Fisher syndrome associated with chronic lymphocytic leukemia
}

\author{
Zeynep Akı, Özlem Aksoy', Gülsan Sucak, Reha Kuruoğlu', Münci Yağci \\ Departments of Hematology and ${ }^{1}$ Neurology, Gazi University Faculty of Medicine, Ankara, Turkey
}

\begin{abstract}
Chronic lymphocytic leukemia (CLL) is a frequent hematological malignancy, with meningeal or peripheral nerve infiltrations being the most commonly encountered neurological complications. In this report, we describe a CLL patient with Miller-Fisher syndrome (MFS) who responded to immune modulation with plasmapheresis. A 47-year-old man diagnosed as B-cell CLL admitted with neutropenic fever. He complained of diplopia and numbness of both arms. Neurological examination revealed a bilateral external ophthalmoplegia, dysphagia, dysarthria, mild shoulder girdle muscle weakness and gait ataxia, accompanied by absent tendon reflexes. Nerve conduction studies were indicative of a predominantly axonal sensori-motor peripheral neuropathy. This association of CLL with MFS had not been previously reported in the literature.
\end{abstract}

Key words: Chronic lymphocytic leukemia, Miller-Fisher syndrome, plasmapheresis

Chronic lymphocytic leukemia (CLL) is a frequent hematological malignancy, with meningeal or peripheral nerve infiltrations being the most commonly encountered neurological complications, albeit rare. ${ }^{[1]}$ Miller-Fisher syndrome (MFS) is an immune-mediated inflammatory neuropathy, characterized by acute onset of ophthalmoplegia, ataxia and areflexia. ${ }^{[2,3]}$ Regarded as a clinical variant of the Guillain-Barré syndrome (GBS), it is usually preceded by a wide variety of antecedent factors, including Campylobacter jejuni enteritis and upper respiratory tract viral infections. ${ }^{[4]}$ Although the association of acute GBS with systemic cancer and hematological malignancies including leukemia has been reported, MFS presenting as a clinical manifestation of tumors is rare. ${ }^{[5,6]}$ Recently, a case of MFS has been reported in the context of Hodgkin's disease. ${ }^{[7]}$ We describe a CLL patient with MFS who responded to therapy with plasmapheresis.

\section{Case Report}

A old man was diagnosed as B-cell CLL, clinical stage Rai IV, in August 2003. In addition to the marked lymphocytosis on peripheral blood smear, flowcytometric analysis of lymphocytes (CD5+,CD19+, CD23+, FMC7-, CD79b-) were also typical for CLL. In the $17^{\text {th }}$ week of high-dose chlorambucil and rituximab therapy (chlorambucil $30 \mathrm{mg} /$ day one to four days/week for the first four weeks and later in combination with rituximab $375 \mathrm{mg} / \mathrm{m}^{2} /$ day with two-week intervals) he was admitted to the hospital with neutropenic fever. He complained of diplopia and numbness of both arms. Neurological examination revealed a left side ptosis and limitation of abduction of the left eye. Deep tendon reflexes were absent. In the course of a few days total bilateral external ophthalmoplegia, dysphagia and dysarthria developed. Pupillary responses remained normal. A slight weakness of the shoulder girdle muscles and gait ataxia were noted.

Microbiological tests for neutropenic fever, serological tests for human immunodeficiency virus, cytomegalovirus, herpes simplex virus, anti-hu and anti-ri antibodies were negative. A cranial Magnetic Resonance Imaging (MRI) study and cerebrospinal fluid examination revealed normal findings. Serum AntiGQ1b ganglioside antibodies were negative. Nerve conduction studies showed a diffuse predominantly axonal sensori-motor peripheral neuropathy. Sensory nerve conduction velocities of the right upper extremity were markedly slow, with absent or reduced sensory nerve action potential (SNAP) amplitudes [Table 1]. Motor nerve conduction velocities were also slow and F-wave latencies were mildly delayed, but outside the demyelinating range, as defined by the American Academy of Neurology criteria [Table 2]. ${ }^{[8]}$ Needle electromyography of the right tibialis anterior and deltoid muscles showed no spontaneous activity. Motor unit action potential morphology was normal. The patient could not perform maximum contraction due to poor cooperation. There was no decrement on repetitive nerve stimulation on the abductor digiti minimi muscle. After a total of six sessions of plasmapheresis every other day neurological examination returned

\section{Zeynep Aki}

Ögretmenler Cad. 470 Sok. 2/16, 06520 Çukurambar - Ankara, Türkiye. E-mail: sahikazeynep@gmail.com 
Table 1: Initial and follow-up sensory and mixed nerve conduction studies. Nerve conduction velocities $(\mathrm{m} / \mathrm{s})$ of the studied segments are followed by sensory nerve action potential amplitudes

\begin{tabular}{lcc}
\hline Nerve & June 2004 R/L & August 2004 R/L \\
Median & & \\
Digit II-wrist $(>39.4)$ & $31.4 / \mathrm{ND}$ & $32.4 / \mathrm{ND}$ \\
SNAP amp $(>10)$ & $2.6 / \mathrm{ND}$ & $7 / \mathrm{ND}$ \\
Wrist-elbow $(>49)$ & $41.2 / \mathrm{ND}$ & $42 / \mathrm{ND}$ \\
SNAP amp $(>10)$ & $3.8 / \mathrm{ND}$ & $12 / \mathrm{ND}$ \\
Elbow-axilla $(>53.2)$ & $44.8 / \mathrm{ND}$ & $46.5 / \mathrm{ND}$ \\
SNAP amp $(>5)$ & $12 / \mathrm{ND}$ & $15 / \mathrm{ND}$ \\
Ulnar & & \\
Digit V-wrist $(>37.3)$ & NP/ND & $34.4 / \mathrm{ND}$ \\
SNAP amp $(>7)$ & NP/ND & $5 / \mathrm{ND}$ \\
Wrist-elbow $(>49.8)$ & $35.6 / \mathrm{ND}$ & $39.6 / \mathrm{ND}$ \\
SNAP amp $(>5)$ & $7 / \mathrm{ND}$ & $7 / \mathrm{ND}$ \\
Elbow-axilla $(>48.2)$ & $36.5 / \mathrm{ND}$ & $42.7 / \mathrm{ND}$ \\
SNAP amp $(>8)$ & $5.5 / \mathrm{ND}$ & $7 / \mathrm{ND}$ \\
Sural & & \\
Sensory NCV $(>33.8)$ & $32.2 / 33.1$ & $38.2 / 34.9$ \\
SNAP amp $(>5)$ & $6.5 / 4.3$ & $7.5 / 7$ \\
\hline R. &
\end{tabular}

R: right, L: left, ND: not done, SNAP amp: sensory nerve action potential amplitude $(\mu \mathrm{V})$, NP: no potential, (numbers in parentheses indicate reference values of our laboratory)

\begin{tabular}{|c|c|c|}
\hline \multicolumn{3}{|c|}{$\begin{array}{l}\text { Table 2: Initial and follow-up motor nerve } \\
\text { conduction studies }\end{array}$} \\
\hline Nerve & June 2004 R/L & August $2004 \mathrm{R} / \mathrm{L}$ \\
\hline \multicolumn{3}{|l|}{ Median } \\
\hline $\mathrm{TL}(<3.8)$ & 3.7/ND & 3.6/ND \\
\hline $\begin{array}{l}\text { Elbow-wrist NCV } \\
(>49.7)\end{array}$ & $44.4 / \mathrm{ND}$ & 44.7/ND \\
\hline CMAP amp (>4) & 10.1/ND & 5.8/ND \\
\hline F-latency $(<32)$ & $36 / N D$ & $34.6 / N D$ \\
\hline \multicolumn{3}{|l|}{ Ulnar } \\
\hline $\mathrm{TL}(<3.3)$ & $3 / \mathrm{ND}$ & 3/ND \\
\hline $\begin{array}{l}\text { Elbow-wrist NCV } \\
(>49.9)\end{array}$ & 46.8/ND & $46 / N D$ \\
\hline CMAP amp (>7) & 7/ND & 6.9/ND \\
\hline F-latency $(>32)$ & 38.4/ND & $33.4 / N D$ \\
\hline \multicolumn{3}{|l|}{ Peroneal } \\
\hline $\mathrm{TL}(<5)$ & $4.9 / 4.8$ & $4.8 / 3.8$ \\
\hline $\begin{array}{l}\text { Knee-ankle NCV } \\
(>40.9)\end{array}$ & $37.7 / 36.3$ & $38.1 / 41.3$ \\
\hline CMAP amp $(>3.5)$ & $5.4 / 4.1$ & $5.1 / 4.2$ \\
\hline F-latency $(>52)$ & $62.4 / 57$ & $59 / 53$ \\
\hline \multicolumn{3}{|l|}{ Tibial } \\
\hline $\mathrm{TL}(<6)$ & $5.2 / 5.9$ & $4.4 / 4.3$ \\
\hline $\begin{array}{l}\text { Knee-ankle NCV } \\
(>39.6)\end{array}$ & $35.8 / 36.1$ & $39 / 39$ \\
\hline CMAP amp (>3.5) & $11.2 / 10.3$ & $7 / 7.2$ \\
\hline F-latency $(>52)$ & $53 / 58.8$ & $56.2 / 55.8$ \\
\hline
\end{tabular}

$\mathrm{R}$ : right, L: left, TL: motor terminal latency (ms), ND: not done, NCV: nerve conduction velocity $(\mathrm{m} / \mathrm{s})$ CMAP amp: compound muscle action potential amplitude (mV), F-latency: F-wave latency (ms), (numbers in parentheses indicate reference values of our laboratory)

to normal, except for the loss of tendon jerks and no relapses occurred until the last follow-up visit in April 2005. A repeat nerve conduction study two and a half months after the first one showed an improvement in all variables, which was most prominent in the SNAP amplitudes.

Miller-Fisher syndrome associated with malignancy has been described in a patient with lung cancer. However, this case showed malignant cells in the cerebrospinal fluid and contrast enhancing leptomeningeal lesions in cranial MRI, most likely due to the meningeal infiltration by the tumor. ${ }^{[9]}$ The other patient described by RubioNazabal et al., ${ }^{[7]}$ is paraneoplastic as ours, responding to immunotherapies. Our case is the first described MFS in the context of CLL and possibly the second paraneoplastic case in the literature. Guillain-Barré syndrome had been previously reported in association with B-cell CLL following mobilization therapy with cyclophosphamide. Although the clinical and the electrophysiological features were not described in detail, this case presented with symmetrical weakness of both upper and lower limbs, without ocular or bulbar involvement. ${ }^{[10]}$ Ocular involvement and marked gait ataxia without predominant weakness in our patient, as well as the absence of convincing demyelinating nerve conduction abnormalities suggested the diagnosis of MFS, although the serological evidence was lacking. Motor nerve conduction velocities were slow in our patient, but within the axonal range. It is of interest that sensory nerve conduction slowing was more prominent than motor, but axonal loss was also definitely present, since the SNAP amplitudes markedly recovered without concomitant amelioration of the sensory nerve conduction velocity in the control examination [Tables 1 and 2]. Durand et al., also reported marked slowing of the sensory nerve conduction velocities $(<80 \%$ of the lower limit of normal), suggestive of demyelination in three of their 10 MFS cases. ${ }^{[11]}$ Toxicity is ruled out, as no toxic neuropathy is reported, neither with chlorambucil, nor with rituximab. Therapeutic efficacy of chlorambucil in combination with prednisolone has also been reported in a CLL patient with post infectious acute inflammatory demyelinating polyradiculopathy. ${ }^{[1]}$ The most likely pathogenetic mechanism in our patient is the suppression of cell-mediated immunity, as this can lead to the development of immune reaction against the peripheral nervous system antigens. ${ }^{[7,10]}$

Therapeutic roles of immunomodulatuary or immunosuppressive drugs including rituximab and fludarabine have not been studied yet in immunemediated neuropathies. Although the therapeutic role of plasmapheresis has not been proven yet in patients with MFS, plasmapheresis may remove antibodies and induce a shift of the Th1/Th2 balance. ${ }^{[12]}$ Although the possible beneficial effects of plasmapheresis have been described especially in complicated MFS in which there is profound ataxia, severe bulbar palsy and respiratory and motor impairment, Mori et al. failed to show the efficacy of plasmapheresis on the speed of recovery in a retrospective analysis of 50 MFS patients. ${ }^{[13]}$ Controlled clinical trials are required to demonstrate the effect of plasmapheresis on MFS as a therapeutic option. 


\section{References}

1. Drake WM, Monson JP, Trainer PJ, Sharief M, Dick JP, Kelsey SM. Acute polyneuropathy with chronic lymphocytic leukaemia and paraproteinaemia: Response to chlorambucil and prednisolone. J Neurol Neurosurg Psychiatry 1998;64:564-5.

2. Fisher M. An unusual variant of acute idiopathic polyneuritis (syndrome of ophthalmoplegia, ataxia and areflexia). N Engl J Med 1956;255:57-65.

3. Willison HJ, O'Hanlon GM. The immunopathogenesis of Miller Fisher syndrome. J Neuroimmunol 1999;100:3-12.

4. Orr CF, Storey CE. Recurrent Miller-Fisher syndrome. J Clin Neurosci 2004;11:307-9.

5. Gorson KC, Ropper AH. Guillain-Barré syndrome. In: Cros D, editor. Peripheral neuropathy. A practical approach to diagnosis and management. Philadelphia: Lippineott Williams and Wilkins; 2001. p. $65-84$.

6. Mailänder V, Gleisner B, Blau IW, Thiel E. Guillain-Barre-Strohl syndrome unraveled as paraneoplastic syndrome of B-cell acute lymphoblastic leukemia in a patient with preceding common variable immunodeficiency syndrome with Evans syndrome. Leuk Lymphoma 2004;45:189-92.

7. Rubio-Nazabal E, Marey-Lopez J, Torres-Carrete JP, Alvarez-Perez P,
Rey Del Corral P. Miller-Fisher syndrome and Hodgkin's disease. J Neurol Neurosurg Psychiatry 2002;73:344.

8. Cornblath DR, Asbury AK, Albers JW, Feasby TE, Hahn AF, McLeod JG, \&al. Research criteria for diagnosis of chronic inflammatory demyelinating polyneuropathy (CIDP). Neurology 1991;41:617-8.

9. Csepany T, Boczan J, Magyar MT, Molnar S, Csiba L, Decsy J, đal. Miller Fisher syndrome: A presenting clinical manifestation of lung cancer in a previously apparently healthy individual. J Neurol 2004;251:898-900.

10. D'Arena G, Vigliotti ML, Pizza V, Tartarone A, Volpe G, Iodice G, \& al. Guilllain-Barré syndrome complicating mobilization therapy in case of B-cell chronic lymphocytic leukemia. Leuk Lymphoma 2004;45:1489-90.

11. Durand MC, Goulon-Goéau C, Schweitzer A, Chéliout-Héraut F, Raphael JC, Gajdos P. Etude électrophysiologique de 10 cas de syndrome de Miller Fisher. Rev Neurol 2001;157:72-9.

12. Kambara C, Matsuo H, Fukudome T, Goto H, Shibuya N. Miller Fisher syndrome and plasmapheresis. Ther Apher 2002;6:450-3.

13. Mori M, Kuwabara S, Fukutake T, Hattori T. Plasmapheresis and Miller Fisher syndrome: Analysis of 50 consecutive cases. J Neurol Neurosurg Psychiatry 2002;72:675-80.

Accepted on 19-10-2007

Source of Support: Nil, Conflict of Interest: None declared. 